\title{
Utilization of Antenatal Care Services in Present Pregnancy among the Women Attending in a Teaching Hospital for Delivery
}

\author{
Thapa M, Yadav S, Bujel K \\ Department of Obstetrics and Gynaecology, Kathmandu Medical College, Kathmandu, Nepal
}

Received: January 28, 2015 ; Accepted: January 2, 2016

Aims: To study attendance of antenatal care services during present pregnancy by pregnant women coming for delivery in a teaching hospital of Kathmandu and to analyze the impact of educational status, age group, gravida (number of pregnancy) and occupation of the women on antenatal care service utilization.

Methods: Uncomplicated, term pregnant women who came for delivery in labour or for induction of labour or elective cesarean section were interviewed using semi-structured questionnaire.

Results: Six hundred and four pregnant women were studied. Antenatal care coverage in studied population was found to be $94.8 \%$ with adequate (four) antenatal care visits in $\mathbf{8 3 . 4 \%}$. Women belonged to 20 to 30 years of age group and higher education status had higher rate of antenatal care attendance whereas women who belonged to labor class (daily earner) had significantly lower rate of adequate antenatal care attendance. Number of pregnancy (gravida) of the women did not show association with rate of antenatal care attendance.

Conclusions: Over all antenatal care attendance in this study is very high. Women of 20 to 30 years of age and higher education status had positive effect on antenatal care attendance, where as women who were daily earner or labour had higher rate of failure to attend antenatal care visits.

Keywords: antenatal care attendance; educational status; gravida; occupation

\section{INTRODUCTION}

Antenatal care is systematic supervision of the pregnancy. ${ }^{1}$ It helps in early detection, treatment and prevention of complications during pregnancy. Therefore, good antenatal care will reduce neonatal and maternal mortality.

In Nepal, maternal mortality ratio (MMR) is 170 per 100000 live births. ${ }^{2}$ Millennium development goal 5 (MDG5) has targeted to reduce MMR by 3 quarter by 2015. To achieve this goal MDG 5 has also targeted to cover at least one antenatal care visit by $100 \%$ and 4 antenatal care visit by $80 \%{ }^{3}$

The coverage of antenatal care is low in our country. According to National Health and Demographic Survey (NDHS) 2011, at least one antenatal care visit is only $58 \%$. In the same survey higher rate of antenatal care attendance is found in urban area than the rural area $88 \%$ Versus $55 \%)^{4}$

\section{CORRESPONDENCE}

Dr. Meena Thapa

Department of Obstetrics and Gynaecology

Kathmandu Medical College, Kathmandu, Nepal

E mail: meenathapa513@hotmail.com

Phone No: 9851060052
Ideally, to have good pregnancy outcome total antenatal attendance needs to be 10 for uncomplicated primi gravida, where as it is 7 for multi gravida. The number of visits will be more for complicated pregnancy. 5

In our country, because of difficult terrain and poor economic status of the people ideal number of antenatal care attendance cannot be offered. So, WHO has revised the number of antenatal visits to the women of developing countries. According to WHO, at least 4 targeted antenatal care visits which are supervised by skilled health personnel is sufficient to fulfill the objectives of antenatal care. ${ }^{6}$

There are different factors that prevent the women from utilizing antenatal care services. Higher age group, higher level of education status and higher economic status of women have positive effect on antenatal care attendance where as higher parity and lack of knowledge have negative effect on number of antenatal care attendance. ${ }^{\text {4, 7-10 }}$

This study was done to study the attendance of antenatal care services during present pregnancy by pregnant women coming for delivery in a teaching hospital of Kathmandu and to analyze the impact of educational status, age group, gravida (number of 
pregnancy) and occupation of the women on antenatal care service utilization.

\section{METHODS}

It was a descriptive, cross sectional study. This study was conducted in Obstetrics and Gynecology department of Kathmandu Medical College over the period of one year from November 2013 to October 2014. The uncomplicated, term pregnant women, who attended the hospital either in labour or for induction of labour or for elective cesarean section were taken for the study. After taking verbal consent they were interviewed using semi-structured questionnaire. They were interviewed about age, education status, occupation, obstetric history and antenatal check up. The data were recorded in Microsoft EXCEL sheet, and analyzed using SPSS version 20. Significance of finding was calculated using Chi square test. $\mathrm{P}$ value $<0.001$ were considered as statistically significant.

\section{RESULTS}

A total of 604 pregnant women were studied. The

mean age of women was 25.6 years ( $\mathrm{SD}+/-3.97)$ with the range of 18 to 38 years. Among the total women $32.8 \%$ were primigravida and $63.2 \%$ were multli gravida.

In this study $94.8 \%$ of pregnant women had antenatal care visit during this pregnancy. Majority of women $(83.5 \%)$ had adequate (four antenatal) visits. Very few pregnant women did not have antenatal visit at all (Table1).

Table 1: Frequency of Antenatal Attendance

\begin{tabular}{|lll|}
\hline Frequency of visits & $\begin{array}{l}\text { Number of women } \\
(\mathrm{N}=604)\end{array}$ & Percentage \\
\hline$\geq 4$ visits & 504 & $83.45 \%$ \\
$1-3$ visits & 69 & $11.42 \%$ \\
No visits & 31 & $5.13 \%$ \\
\hline
\end{tabular}

Majority (83.2\%) of women belonged to age group of 20 to 30years. Antenatal care attendance was more than $94 \%$ in all age groups except in women who belonged to the age group of 19 years and below $14.5 \%$ of younger women had no antenatal visit at all. However, inadequate antenatal visits were seen

Table 2. Age group of the women according to antenatal vistls

\begin{tabular}{|llllll|}
\hline Age group & Number of women $(\mathrm{N}=604)$ & $\begin{array}{l}\text { ANC visits } \\
\text { (4 visits }(\mathrm{n}=504)\end{array}$ & 1 -3visits $(\mathrm{n}=69)$ & No visits $(\mathrm{n}=31)$ & P value \\
\hline$\geq 19$ years & 21 & $18(85.7 \%)$ & 0 & $3(14.3 \%)$ & \\
$20-25$ years & 204 & $175(85.7 \%)$ & $17(8.3 \%)$ & $12(5.9 \%)$ & \\
$26-30$ years & 297 & $248(83.5 \%)$ & $34(11.4 \%)$ & $15(5.1 \%)$ & \\
$31-35$ yrs & 62 & $49(79 \%)$ & $12(19.4 \%)$ & $1(1.6 \%)$ & 0.013 \\
$>35$ yrs & 20 & $14(70 \%)$ & $6(30 \%)$ & 0 & 0 \\
\hline
\end{tabular}

Seventy five percent of the studied population had secondary and higher level of education. Those women who had higher level of education they had significantly higher rate of antenatal care attendance than those who were illiterate and had received only primary education. There were no cases of failure to visit antenatal care services among women who were graduated. Failure to receive antenatal check up was seen only in women belonging to low education status.

Table 3. Antenatal care attendance according to education status

\begin{tabular}{|c|c|c|c|c|c|}
\hline \multirow[t]{2}{*}{ Education level of women } & \multicolumn{2}{|l|}{ Total women } & \multicolumn{2}{|c|}{ Number of ANC attendance } & $\mathrm{p}$ Value \\
\hline & $(\mathrm{N}=604)$ & No visit & $1-3$ visits & $\geq 4$ visits & $<0.001$ \\
\hline Illiterate & 77 & $9(11.69)$ & $16(20.77 \%)$ & $52(67.53 \%)$ & \\
\hline Literate/Primary education & 75 & $9(12 \%)$ & $13(17.33 \%)$ & $53(70.6 \%)$ & \\
\hline Secondary education & 326 & $13(4 \%)$ & $33(10.1 \%)$ & $280(85.9 \%)$ & \\
\hline Graduate/Above & 126 & - & $7(5.6 \%)$ & $119(94.4 \%)$ & \\
\hline Total & 604 & 31 & 69 & 504 & \\
\hline
\end{tabular}

Among the studied women, majority $(81.6 \%)$ were either teacher or non-gazetted officer or house wives. The women, who were involved in labour class (daily earner) had significantly lower rate of adequate antenatal care attendance than women who involved in other occupation and housewives $(\mathrm{P}=<0.001)$. They also had higher rate of non attendance of antenatal care service (Table 4). 
Table 4. Antenatal care attendance by occupation

\begin{tabular}{|llllll}
\hline Occupation of women & \multicolumn{2}{l}{$\begin{array}{l}\text { Total women } \\
(\mathrm{N}=604)\end{array}$} & No visit & $1-3$ visits & $\geq 4$ visits \\
\hline Professionals/large scale business & 28 & 0 & $1(3.6 \%)$ & $27(96.4 \%)$ \\
Teacher/Gazetted officer/Small scale business & 209 & $11(5.3 \%)$ & $8(3.8 \%)$ & $190(90.9 \%)$ & P value \\
Farmer/non Gazetted officer & 70 & $4(5.7 \%)$ & $2(2.9 \%)$ & $64(91.4 \%)$ & \\
Labour & 12 & $1(8.3 \%)$ & $7(58.3 \%)$ & $4(33 \%)$ & \\
Housewives & 285 & $15(5.3 \%)$ & $51(17.9 \%)$ & $219(76.8 \%)$ & $<0.001$ \\
\hline
\end{tabular}

Two thirds of the studied women were multigravida. But, similar rate of antenatal care attendance were found in both groups of women (Table 4).

Table 5. Number of pregnancy (Gravida) of women and antenatal care service attendance:

\begin{tabular}{|c|c|c|c|c|c|}
\hline \multirow{2}{*}{$\begin{array}{l}\text { Number of pregnancy } \\
\text { (Gravida)of the women }\end{array}$} & \multirow[t]{2}{*}{ Total Women $(\mathrm{N}=604)$} & \multicolumn{3}{|c|}{ Number of Antenatal attendance } & \multirow[t]{2}{*}{$P$ value } \\
\hline & & No visit & $1-3$ visits & $\geq 4$ visits & \\
\hline Primi gravida & 198 & $11(5.6) \%$ & $19(9.5 \%)$ & $168(84.8 \%)$ & \\
\hline Multigravida & 406 & $(4.9 \%)$ & $50(12.3 \%)$ & $336(82.8 \%)$ & 0.742 \\
\hline
\end{tabular}

\section{DISCUSSION}

The coverage of antenatal care (ANC) attendance in studied population is $94.8 \%$, with $83.4 \%$ of adequate antenatal care visit. This finding is better than national antenatal care coverage which is only $58 \% .^{4}$

A study done in Tamang community of Hilly area in central Nepal showed $78.9 \%$ of antenatal care coverage, but adequate $(\geq 4)$ antenatal care visit was found only in $46.4 \%$ of women. ${ }^{11}$

According to the National Demography and Health survey (NDHS) 2011,4 ANC coverage is only 58\% in our country. ${ }^{4}$ Whereas, a national representative study done by reviewing the individual data record of National Demography and Health survey (NDHS) 2006, had shown that failure to antenatal care attendance by $27.76 \%$ of women. ${ }^{9}$ Similar study was also done by reviewing the National Demography and Health Survey 2011 (NDHS 2011), which showed that failure to attend antenatal care check up has improved in 2011. However, failure to attend antenatal care visits was still in $15 \%$ of women. Besides that, adequate number of visits has also increased $(50 \%)$ over the period. ${ }^{10}$

As in Nepal, most of the developing countries have less coverage of antenatal check up. In a study done by $\mathrm{Ye}$ et $\mathrm{al}^{12}$ showed that there was no antenatal care checkup in last pregnancy by $53.9 \%$ of women of Laos. But the study done by Abosse et $\mathrm{al}^{8}$ found that antenatal care coverage in Ethopia is higher than Nepal which is $86.3 \%$ with adequate antenatal care attendance of $42 \%$.

In our study, women belonged to age group of 2030 years had higher rate of antenatal care attendance.
But, a study done by using the demographic and health survey data ${ }^{10}$ had found that women of older age group had higher rate of antenatal attendance in Nepal. A study done by Agus and Horiunchis ${ }^{7}$ in Indonesia had also shown that higher rate of antenatal care attendance was seen in women of $>35$ years of age and lower rate of antenatal visits were seen in women of 20- 35 years of age.

Education status of a woman has direct impact on utilization of ANC services during pregnancy. It is found that women of higher education status had higher rate of antenatal care attendance. In our country, the women who had education of SLC or above had antenatal care attendance of $89 \%$ and antenatal care attendance were found only $15 \%$ in women of no education. ${ }^{13}$ Mean number of antenatal visits were found more in women of higher education level than the women of no education, which has found on analyzing the individual record of NDHS 2006. ${ }^{9}$ Analysis of individual records of NDHS 2011 also found that higher $(85 \%)$ antenatal care attendance were found in women of higher education status, ${ }^{10}$ which was similar to the study done in Kathmandu valley. ${ }^{14}$ The positive impact of education is found not only in Nepal, but also in other developing countries. ${ }^{15}$ Whereas, the study done by Sadique et $\mathrm{al}^{16}$ in Pakistan had found no association between ANC visits and education level of the women; instead husband's education had positive impact on ANC attendance. This study showed that daily earner/ labour had lower rate of antenatal care attendance than those who were in other occupation and housewives. A study done by analyzing the individual records data 
file of NDHS 2006, had shown that women who does not involve in formal work (housewives) had higher mean antenatal care attendance than those who work ( 3.18 versus 2.22 visits). ${ }^{9}$ In contrary to this finding, another studies showed that those who were involved in formal work had higher antenatal care attendance than those who did not work. ${ }^{10-14}$ It may be due to varied study population in different studies.

Parity of women is also an important factor in antenatal care attendance. Higher the parity, more the antenatal care attendance were seen in studies. ${ }^{10}$, But, Pradhan ${ }^{14}$ and Simkhada et $\mathrm{al}^{15}$ had found that antenatal care attendance had decreased as the parity increases. Pradhan ${ }^{14}$ also found that adequate ANC visits were more in women of lower parity. Contrary to these studies, this study failed to show any association between gravida of the women and antenatal care attendance.

\section{CONCLUSIONS}

Over all antenatal care attendance in this study is nearly $95 \%$ with adequate antenatal care attendance of $83.4 \%$. Women of 20 to 30 years of age and higher education status had positive effect on antenatal care attendance, whereas women who were daily earner or labour class had higher rate of failure to attend antenatal care visits. Gravida of the women did not show relationship with antenatal care visit.

\section{REFERENCES}

1. Dutta DC, Hiralal Konar. Antenatal care, pre-conceptional counseling and care. In: Textbook of Obstetrics.7th ed. Kolkata: New Central Book Agency (P) Ltd; 2011.p.100

2. WHO. Trends in Maternal Mortality: 1990 to 2010 Switzerland. WHO, UNICEF, UNFPA and the World Bank. 2012 .

3. Millennium Development Goals Improve maternal health, where we are? Sustainable Development Goals Page [Internet]. Nepal: UNDP; 2015. Available from: www. np.undp. mdg5ht

4. Ministry of Health and Population (Nepal), New ERA, and ICF International Inc. Nepal Demographic and Health Survey 2011. Kathmandu, Nepal. Ministry of Health and Population (Nepal), New ERA, and ICF International, Calverton, Maryland. 2012.

5. Antenatal Care for Uncomplicated Pregnancies [Internet] 2008 March [Updated 2016 March]

6. Birungi $\mathrm{H}$, Onyango-Ouma W. Acceptability and sustainability of the WHO focused antenatal care package in Kenya. Frontiers in Reproductive Health Program, Population Council (Kenya) and Institute of African Studies, University of Nairobi (Kenya); 2006 June.

7. Agus Y, Horiuchi S. Factors influencing the use of antenatal care in rural West Sumatra, Indonesia. BMC Pregnancy Childbirth. 2012 21;12:9.

8. Abosse Z, Woldie M, Ololo S. Factors influencing antenatal care service utilization in Hadiya Zone. Ethiop J Health Sci. 2010;20:75-82.
9. Shrestha G. Factors related to utilization of antenatal care in Nepal: a generalized linear approach. JKMC. 2013;2: 69-74.

10. Joshi C, Torvaldsen S, Hodgson R, Heyen A. Factors associated with the use and quality of antenatal care in Nepal: a population-based study using the demographic and health survey data. BMC Pregnancy Childbirth. 2014;14: 94.

11. Sanjel S, Ghimire RH, Pun K. Antenatal care practices in Tamang community of hilly area in central Nepal. Kathmandu Univ Med J. 2011;9: 57-61.

12. Ye Y, Yoshida Y, Harun-Or-Rashid M, Sakamoto J. Factors affecting the utilization of antenatal care services among women in Kham district, Xiengkhouang province, Lao PDR. Nagoya J Med Sci. 2010;72: 23-33.

13. Shrestha G, Shrestha G. Statistical analysis of factors affecting utilization of antenatal care in Nepal. Nepal J Sci Technol. 2011;12:268-75

14. Pradhan A. Situation of antenatal care and delivery practices. Katnmandu Univ Med J. 2005;3: 266-70.

15. Simkhada B, Teijlinger ER, Porter M, Simkhada P. Factors affecting the utilization of antenatal care in developing countries: systematic review of the literature. J Adv Nurs. 2008;61: 244-60.

16. Sadiqi N, Waheed Q, Hussain M, Rana AT, Yousaf Z, Chaudry $Z$ et al. Factors affecting the utilization of antenatal care among women of reproductive age in Nurpur Shahan. J Pak Med Assoc. 2011;61: 616-8. 